\title{
Flipping the third space
}

\author{
Robyn Markus-Sandgren \\ Library Manager, Senior Library, \\ Gold Coast, Australia \\ library@sthildas.qld.edu.au
}

\begin{abstract}
Our school faced a particular problem. As in many other schools, teachers and students are increasingly mobile savvy and internet connected while at school. This affects how teaching is done and how libraries are used. In response proposed to bring the Library to the classrooms. We would move the existing library, from its own building, to share the center of the action, into learning spaces once occupied only by classrooms. While the digital integration had already begun, the physical integration would serve both the traditional and new ways in which libraries can be used. We propose that both library and classroom practices will be "flipped" so that putting ideas and information into action and thinking about what you have learnt will become the focus, using the new library to extend and enrich that practice. This paper will report on the practical implications and experiences of such an undertaking. In addition, the paper will outline some of the research concerning how the elements of the learning process are distributed across the day.
\end{abstract}

Keywords: Flipping, Third space, School libraries

\section{Introduction}

In March 2011 Australia's House of Representative Committee on Education and Employment submitted a report on school libraries in Australia (Australia \& Rishworth, 2011). The report consists of comments and recommendations about what school libraries in Australia could be like and what issues they face. In preparing to submit a statement to the committee, I engaged in an actual conversation with my Head of School about our library. He understood that the bustling library that we had did not come about on its own. He spoke of the fact that both parents and students wanted and used such a safe in-between space. He was also glad that I was not one of those teacher-librarians who attempted to tell him how to research in his own area and with his students. In the main, his comments seemed representative of the general attitude towards the library and library staff, across the whole school. What they wanted was not a library that led change and innovation, but one that support these as they occurred in teaching and learning, as a library. An example is found in the work of Tiffany Williams who looks at factors that might inhibit a student's inclusion in STEM subjects and explores how a library might help (2013). Our school, a girls' school, is introducing STEM subjects. We ask how could our library respond to and support more girls to be included.

In the half decade that followed, therefor, this has been the central tenant of my approach. There is plenty of work to do resourcing and supporting teaching and learning by being informed and responsive enough, IT ready and have the skills to do so. A second arm of the 
work of the library is a co-curricular engagement with students and their reading and thinking. This arm has not been supported, in the main, but it has been tolerated by the teaching staff and roundly embraced by the students. Most importantly, it has allowed the library staff to better know the students. Crucially, also, it has prompted me to consider more closely the library's role for student learning and how this sits with negotiating a place for student interests outside the curriculum, in the library. So the idea of the library as a third space came about, as it has done for many others, mainly in higher education and in public libraries (Ali, 2013). I became excited!

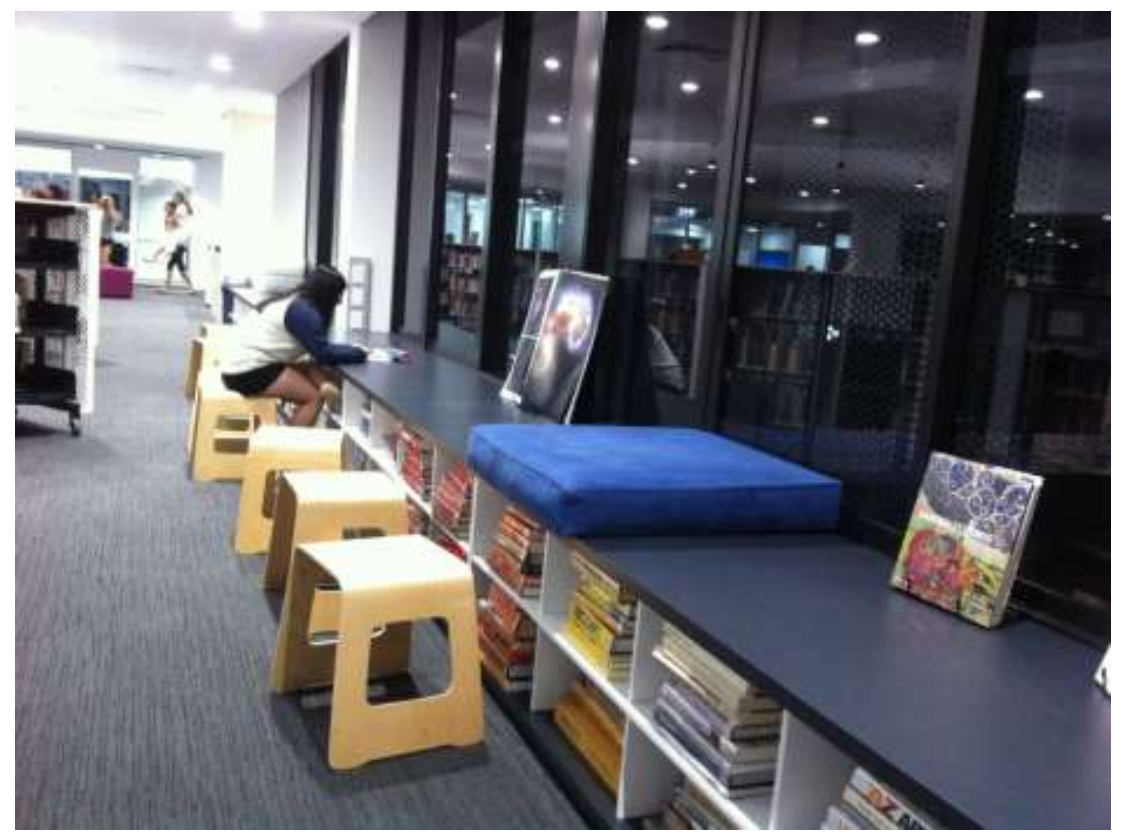

The color coordinated big books... one solution to beautiful but impractical shelving

It is, perhaps, complimentary to a library when everyone who uses it feels as if it is theirs, and that they understand and use it as if it was theirs. Many feel perfectly able to speak for it and also, surprisingly, pronounce advice as if, should they be the manager of the library, that it would be no harder than organizing the books and materials on their own home shelves. Happily, readers feel like you are their best friend and continue to marvel at the wonder that is a library, concerned to lose the old one but hopeful for the new one, because of the ongoing relationship of trust and sharing they have with you. Non-readers feel sorry for you because you are managing a dying space that, though noisy with people, belongs to yesterday. They look blankly at the book shelves and are deaf to the sound of collaboration, conversation and concentration. They don't notice the sound of keyboards, the play of fingers on touch screens, the sight of paper being turned and written on, and the hum of people engaging with their work and relaxing; not hearing, perhaps, because of the "airport" music keeping buoyant a steady quietness. 


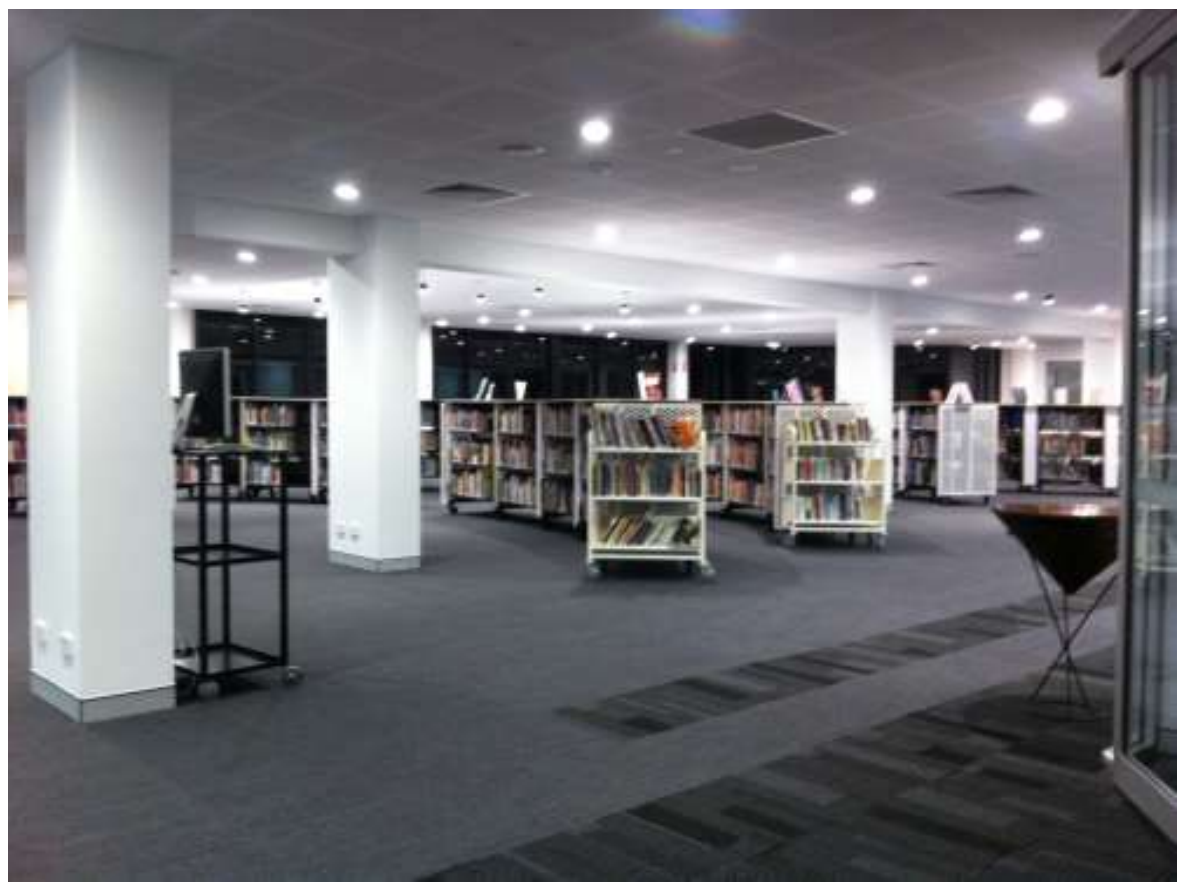

The long view north

The IT Staff believe that Library technologies work at the kindergarten level of their expertise and that you are not part of any of the great trends in education, let alone technological innovation and expertise. If you need something technological they hope that if they leave it long enough you will give up or, be found technologically inept and be able to justify their perceptions. So great is their confidence in their own skills and beliefs that they are willing to lie to you and to others about you and, if you've established a level of independence from them as I have, they are then actually confirmed in their belief that nothing important technologically speaking occurs in a library.

The preconceptions about what a library is have remained with staff far more than with the students. Students flock to use the space in old and new ways, morning to night. The students, when not in subject classes, have already turned the Library into a Third Space. However, the capacity of the library to evolve and deliver to its potential has remained constrained by both the existing library space and by how the library is seen in the mind's eye of many educators and administrators. With the exception of the Senior History teachers, most rarely set foot in the old Library, which was separate from the teaching areas and staff rooms. Even though the library has evolved, is online and provides access to digital print and streamed video material as well as assignment research help digital portfolios, many teachers have stored their own collections in their own offices and network places, are reluctant to try and quick to condemn other technologies, sites or collections and deliberately limit their students to just the resources and research methods with which they are familiar. They, on the whole, consider the process of search, discover, reflect and create a waste of valuable time, unless it is to Google something for a quick level one answer. They believe that they have the technology and the specialist expertise to deliver all that their students need and, if they do not need the library anymore, why should the students? So, while the vast majority of staff view the library as only good for baby-sitting classes, for after school 
care or for troubled loners seeking escape from the real world, students find the library a comfortable, safe, welcoming and interesting place to work, seek academic support, interact and meet, despite its reputation as a space for those not ready for the twenty first century.

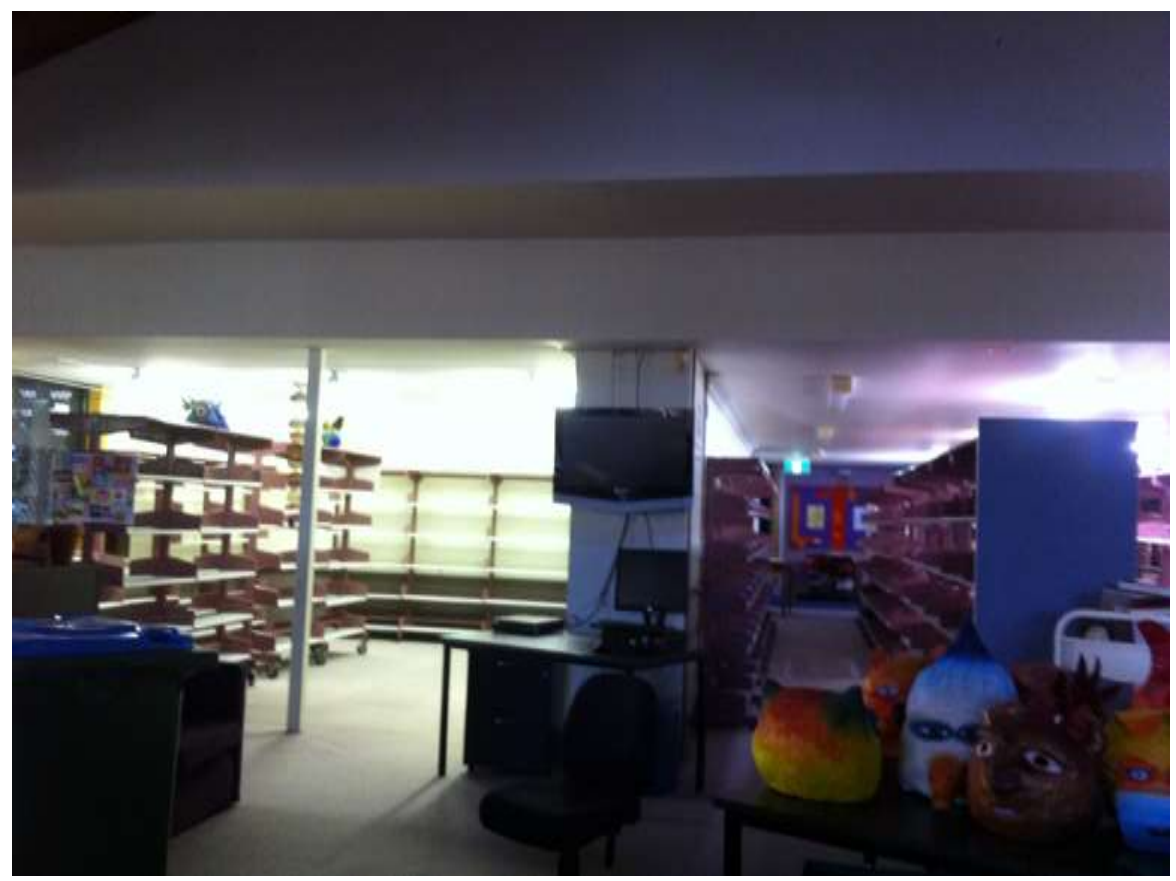

The old library, nearly empty now

When it was announced that a 1980s teaching block for the senior students was to be renovated I saw a chance for the transformation of the Library into what I felt, what the professionals were saying, it could be. I decided that the Library should be part of the renovations, part of the thinking about what teaching and learning spaces could be like and part of a reconfiguration of the relationship between The Library and The Classroom. I looked at the L-shaped block and thought and asked, could we make the two above ground floors rectangles and one of the rectangles, flanked by an $L$ of classrooms, could this become the Library? What if the library came to classes and teachers rather than them coming to the library? What if the library became an everyday part of teaching and learning? For my Head of School, a History teacher, the idea came alive immediately. We decided to test the idea. By knocking down a wall that divided two classrooms off from the old Library and timetabling them as permanent rooms for the Humanities, these classrooms and the Library became one. For the two years of the planning and building of the new Senior School teaching area, we have been able to test how the idea works and feels and to reflect on what the idea means for our library and for teaching and learning at St Hilda's. For those involved it was a resounding success and did much of the initial leg work needed to communicate the basis of the idea of the new library.

People not involved were surprised and shocked that I would give up the library space for something unknown. Just about everyone, even those who felt sorry for your lost status in the new world of the whiz bang, still wanted there to be a library and were worried that it would disappear. The hip teachers, as they undertook further and field studies, started 
sending links and article references, ideas and advice from experts in their fields, about libraries. Just formulating the idea of uprooting the library and replanting it ready for engaging with the classrooms took effect, even before the first book left the old library for its new home.

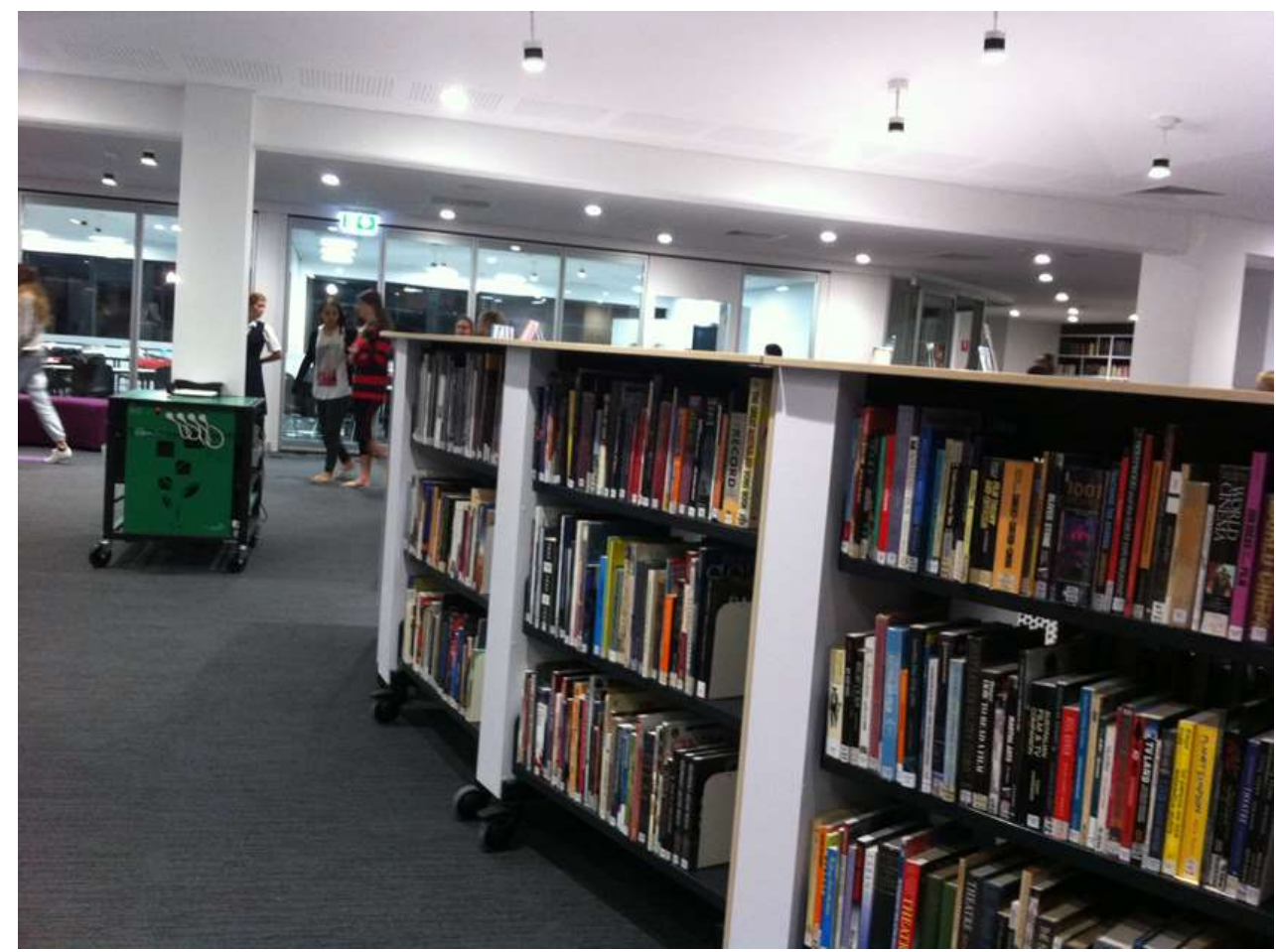

Curved shelves on wheels and the laptops for loan trolley

\section{Ideational reflections}

Life's spheres are many and varied. In a modern education each sphere has developed sets of knowledge, skills and concepts that underpin and define expertise. Following an industrial model, this warehousing of specialty areas seemed to be required to meet the sheer volume and growth of specialized skills and knowledge. However, along with technology, teaching and learning have evolved, especially over the last decade or so, and as the works of Rajala et al (date?), Zipin (2009), for example, reveal, there are significant inter-dependencies and, now, significant movement between different spheres of learning in and beyond schooling. Established programs and practices are being challenged in the light of a vastly different world of work and further learning. The citadel style is questioned because the evolution from a modern to a post-structural model is part of a more general evolution towards privileging relationships between knowledge, intentions and ideas from different spheres. Theorists of Complexity may call this anthropogenic complexity. This re-privileging is seen to empower young learners in a globally connected world. Yet to see oneself as part of this connected world and for others to see you as part of it too, remains problematic. The author proposes the view that the power and privileges of professional specialty seem to be threatened rather than informed in the process and "it is judged unsafe to stop pretending" (Strand, 2007, p.210). I give testament to the legacies of a generous and insightful education and thoughtful and literate, peopled spaces, especially at school and at university, 
for incubating the idea that the world is learnt about in particular but understood and engaged with as a whole, that connections that matter occur both within and between things. As Rajala et al further explain, many different learning modalities play together and many different communities of practice interact in learning, across individual and group development and across time and space (2013). I looked for understanding that felt whole, first in my own learning, then in teaching and now in Library Management practice. I am driven to find ways of meaning and sense-making that are more connective, collaborative and inclusive and yet still go deep, to the undercurrent where the facts, or perhaps simply, the individual voice, resonate in the whole of experience.

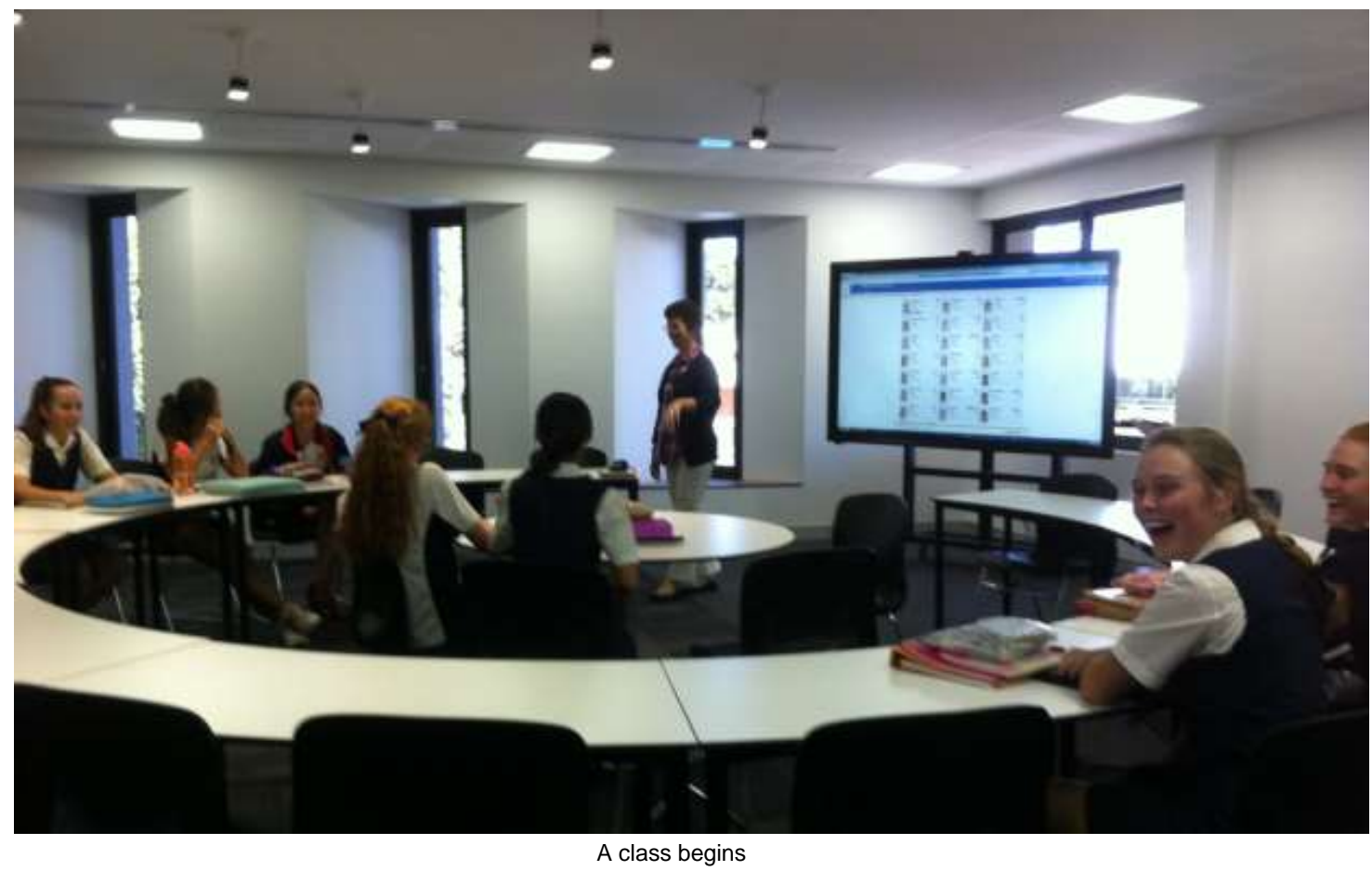

School library practice supports this quest. It is a reflective quest, which constantly references its resource provision, its processes and its space to the wider educational vision of individuals, schools and the communities from which and into which our students venture. Beyond my single professional experience there is significant educational research and practice about connecting in and out of school learning spheres as well as intermittent drives to make cross-curricular connections part of pedagogy. Two examples highlight the point. Most of our teachers are successful modernist specialists and the pushes to link learning across the subject areas are rarely greeted enthusiastically. The linking of the Visual Arts, Science and Geography, for example, with teaching about the environment is an example. In the individual subject areas, the technicalities of using visual language in Art or Media, the teaching of scientific research and report writing in Science or of doing field work in Geography subsume the seemingly obvious connections between the learning directions. Also, importantly, students bring to the classroom out of school learning and experience that affect their learning. Schools, in attempting to create a supportive culture for learning, often risk alienating difference, rather than developing inclusive practices. The reasons for doing so are many and varied and often framed as being in the interests of the child. At the broader policy making level, the Australian Government, applying thought to Australian 
Indigenous Peoples' education states, "A good education ... helps keep culture strong and enable[s] future generations to share stories about their community, culture and kinship." http://www.indigenous.gov.au/children-and-schooling In support of this statement is a swathe of national and international research ( Rolstad et al, 2005) that bilingual programs are effective for promoting academic achievement amongst non-national home language learners. Australian Indigenous people speak many languages, so that when entering school English is often not their first or home language. Yet the "First Four Hours in English" policy went forward in 2012 in the Northern Territory. The policy insisted that only English was to be used to teach during the first four hours of school each day. It was supported politically at the National level and the teaching of home language and culture was, arguably, relegated to an after school activity. The spheres of national testing results, of employment figures, of public perception, of business or of polling were privileged in almost complete disregard of the contexts and the research in which successful Indigenous schooling operates. Indigenous student attendance rates dropped markedly and the policy was dropped. However, the perceptions of being threatened and disregarded remain and a world that had been whole was separated out into bits in order to legislate, promote, teach, and document learning, while the aspects of the process that make learning whole and, actually, efficient (but not cheap), were disregarded.

Despite the isolation in which many educational projects are designed, carried out and reported, each individual child and each sphere in which she sits is a site for multiple intersections, points of resistance and of opening, when learning occurs. Clearly, existing relationships between spheres can both hinder and/or promote learning and connection. When the traditional class has ended, when and where is the knowledge and thinking explored again? In the corridor, with friends and family, tutors, in the playground, in social media and on the internet in general, while doing paid work, playing sport or reading, while studying to pass tests, create works and complete assignments, students' school learning is either left behind or used and remade. What is a space like that supports the individual child to integrate and to powerfully make "new" school based learning, for themselves and in connection with their world? The project to integrate the Senior Library into the teaching spaces of the new Jennifer Reeves Building is an attempt to create such a Third Space and to be part of teaching and learning doing the same.

\section{The process}

Once the main principles had been agreed upon, designs and funding were sought for the whole building: on the Ground Floor, a cafeteria, coffee shop, radio station, Year Twelve space and small performance area; on the First Floor, the Senior School offices, 6 classrooms, recording spaces as well as informal seating, a print station and a self-catering space and on the Second Floor, the Library, print station and 7 classrooms. All these floors were to be linked via internal and external stairways and a lift. Each floor is multi-functional, yet integrated and this made the consultation process enormously complicated. Complexities were over simplified and consultation minimized as a management style. The overall appearance was considered in detail, while the functional aspects were left languishing. Before planning had even begun came the questions like, "Why give up the old building?" and "Was the Library going to lose space?" etc. These questions were asked out of genuine concern or to confirm an individual's perceptions. Few understood that behind the decision lay theoretical and practical principles, experience and reflection and a body of knowledge and research that supported the decision. It was good to begin to be able to articulate a little 
of what actually lay behind the decision but, perhaps not surprisingly, did little to allay the thought that this was the inevitable end of the library and for others that this was part of a conspiracy to hasten its end.

For the Library itself there were three main focuses:

1. The specialist technology and furnishings that linked the security software to circulation tasks. How could we use this technology to free library staff for more supportive and less purely functional roles?

2. The shelving design and layout. What happens to Dewey when you break up the warehouse style in shelving design?

3. Furnishings that would support Third Space interactions. As the classrooms were opening up to the Library, so the library would provide additional spaces for the classrooms. Would both be transformed in the process?

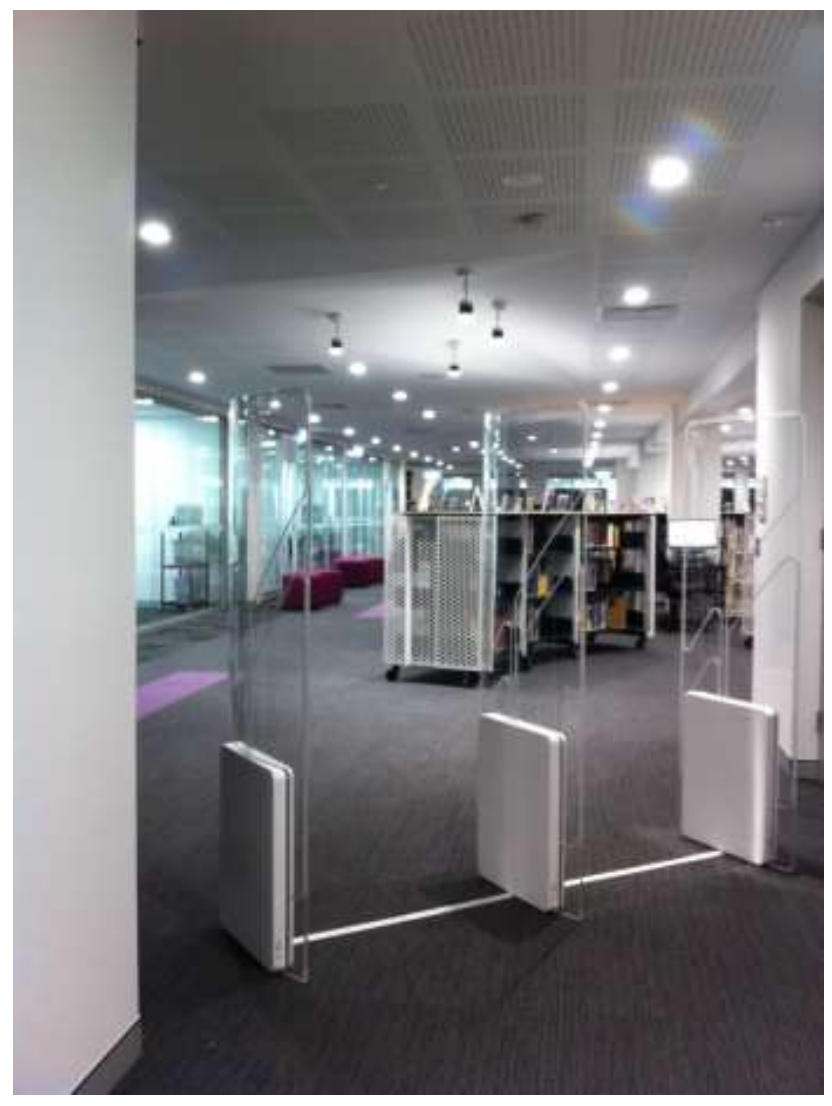

From the Main Entrance, classrooms to the left and straight ahead

1) As the external structure came into being, the block, as it looked then, with scaffolding all round, seemed shrouded in mystery and engineering issues. The existing roof, which was to be used as part of the renovated structure, was deemed unsafe and a new one redesigned while the old one was entirely removed. It must have seemed that the macro level problems would be the most problematic, though library practice has demonstrated that the details can be at least equally demanding. Consultations about the infrastructures that enabled the functioning of the various spaces were, supposedly, 
discussed: telephone lines, TV aerials, network and power points, Wi-Fi, air conditioning, toilets and plumbing, staff and meeting area needs, numbers and styling of classroom desks and chairs and what technology was going to be repeated across the classroom spaces throughout the main construction period. In some areas there was a shared pool of knowledge and experience or a degree of influence that sometimes helped ideas reach decision making table intact. However, as the infrastructure needs for the Library began to be discussed it became clear that, where the needs applied to specifically the Library, a collective blindness and deafness existed. Just as people have home libraries, so many have security gates, right? It couldn't be that hard ... The architects, engineers, builders, the electricians, the IT people, everyone from the project managers to the maintenance personnel felt as if they had enough of a handle on the functioning of a library to get by. So profoundly confident were they in their own skills and beliefs that, during two years of infrastructure planning and building, not one person consulted about nor interpreted correctly the provided detailed library technology specs or my implementation plan and recommendations. In addition to the technology implementation specs, our library security technology provider supplied individualized advice about how the security hardware might best be placed as well as any design issues they foresaw from our architects drawings. Even so, and despite early documentation and numerous revisits, ultimately the external library chute was left off the final drawings. This necessitated a complete re-think of how library returns might best be managed at a time when all other layouts and furnishings were being finalized. The security gate infrastructure was mismanaged: data points were left in the wall, the electric wiring routed incorrectly and the conduit, embedded in the concrete floor for the antenna wires, led away from, rather than between, the gates. The benches for the self-check machines were also removed from the final drawings at some point.

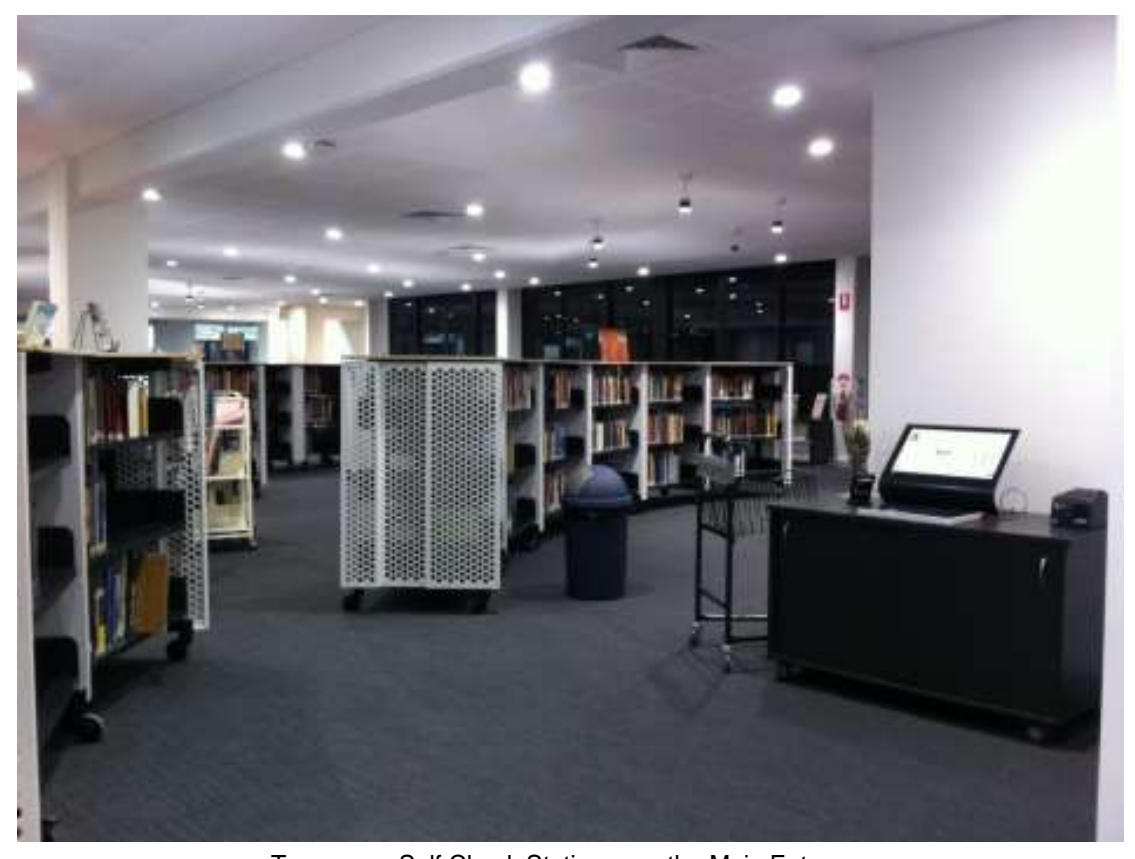

Temporary Self Check Station near the Main Entrance 
The pre-conceived notions that the needs of the Library were all non-urgent and could be solved with ease when they got to them meant that errors in executing the infrastructure were compounded in the work-arounds in small and large details. The errors were characteristic of a lack of consultation and enquiry as much as unforeseeable error. Switches, data points, virtual windows, towers, screens, furnishings etc., all okayed, all incorporated into a plan, nearly all eventually met the same end- an unapologetic no way, not now.

As the Library was completed last and as I was not included in every meeting in which decisions were made about the Library, these matters led to an extremely uncomfortable final period. The very principle of collaboration that the new Library sought to embody was denied it, at least in part, in the planning and also in the execution. Even when others have the final say and pay the final bill, unless stakeholders are fully included, these types of issues are likely to confound the work.

Clearly, it was not sufficient to present and contribute experience and some expertise, experts' plans and concerns, insights and ideas at crucial points. In retrospect, I needed to be present for the process, rather than handing over the details politely to the experts, expecting they would engage with them as thoroughly as was required. The same process error that keeps learning separated into subject areas, classrooms and times, applied in the building of the library. Expertise is needed, but so is free and fearless communication. There is so much to be learnt from each other. This insight has further confirmed and informed what my concept of the Library as a third space means. There should be a sense in which the Library is a space which grants the freedom to work, connect, be heard or relax without privileged influence being applied. A space where decisions are made and the process observed and participated in. What is a space like that has students engaged in thinking, relating and learning by choice? A reversed Frankenstein?

2) Even though the new library was to be a sleek and modern, clean lined space, there was a sense that the mood of a library should not be lost completely. To this end, a space was created with bookshelves built in, creating an air of permanence and a feeling of relaxed lounging and, hopefully, slow thinking and reflecting. It is a unique space in the whole of the three floors. It is lower lit, not Wi-Fi connected and not part of the traffic of teaching and learning activities. At the same time it is not cut off from the rest; the easy transition symbolizing the intention to relate to the past, present and future in one space. It is intended that this space will also be an overtly inviting space for our Indigenous students, though this is a tender and fraught vision. The shelving was designed specifically to create the space. 


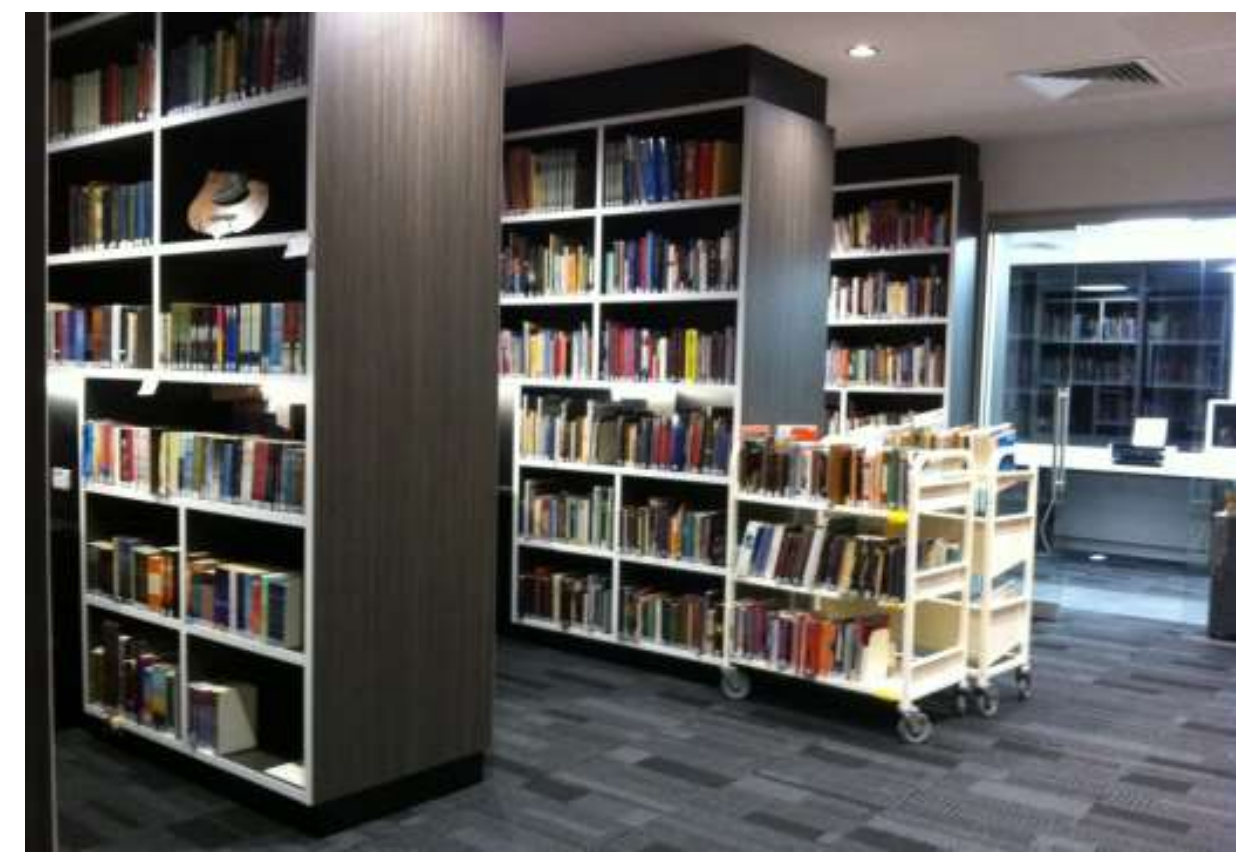

The Lounge Room with shelving overflow \& without the lounge

The main part of the library was to have curved shelving, on wheels, in the industrial style. They are aesthetically pleasing and offer flexibility. Navigating the curves for search and shelving functions is going to be interesting. We are now in the process of designing signage.

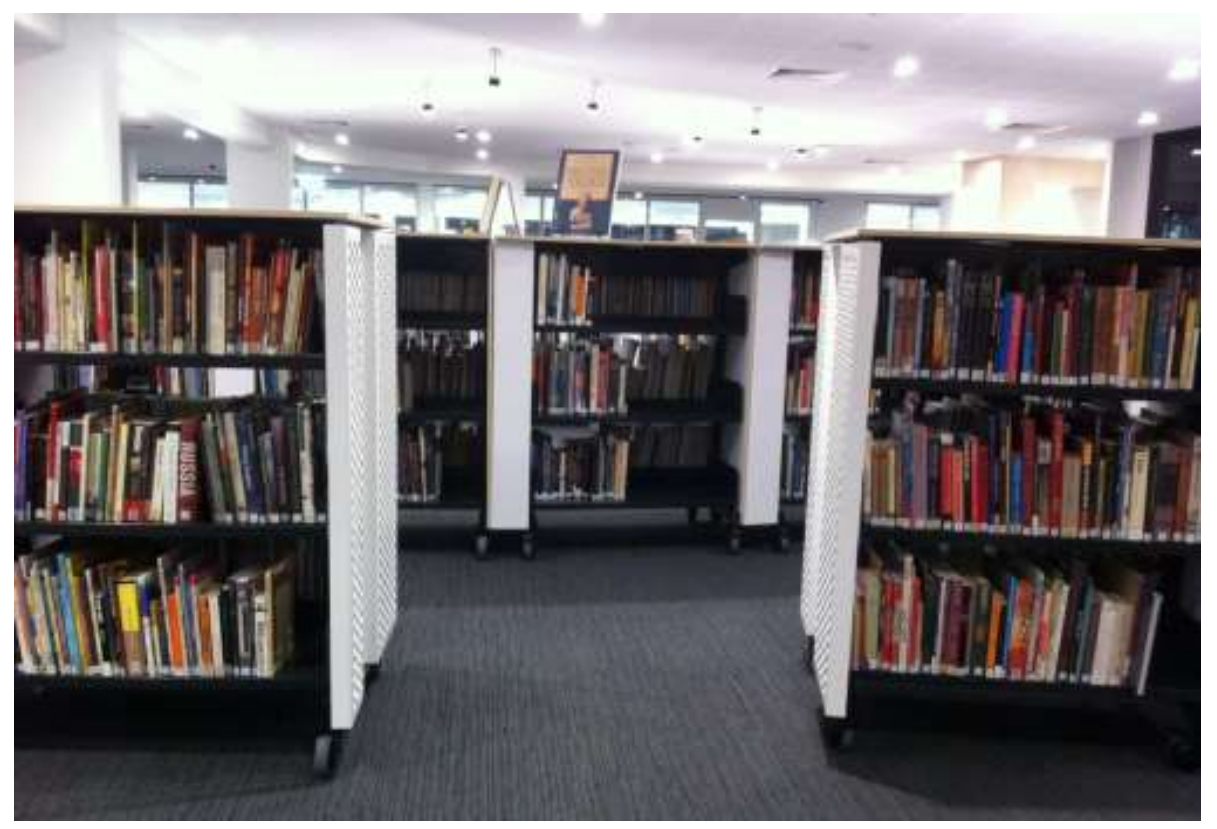

The perception that moving the library was not simply about moving books across the courtyard and onto new shelves, proved to be difficult to change. Notwithstanding this, the sheer quantity of physical work involved was looked upon with concern. 
Ultimately only about half of the required new shelving was actually able to be used effectively or delivered, when the books were to be moved. When the lift was not available on time and the quote and time to move increased accordingly, the professional removal group was cancelled and students were asked to help move the books, earning $10 \mathrm{c}$ a book for charity. The theory behind the decision was to help create a sense of student ownership of the Library. In practice, the students had no idea that both the order and the spacing of the books mattered, that the books were to be cleaned and that some of the old shelving needed to be dismantled and reassembled before some books could be moved. Some of the group of helpers held ongoing discussions with their teacher leaders about how much each book moved was actually worth, as well as how to move the books more efficiently, feeling that the library's concerns were simply slowing them down.

In this particular scenario, the intersection of a complex of theoretical, social, school political and economic factors can be seen. Also visible is the lack of reference to the facts about how a library is actually structured and functions in the present nor any conceptualization of how it might be transformed. If it is OK to simply use the internet without understanding how it works, uploading to YouTube and social media as events happen, then why is it not the same for books? If you can find books on your own home shelves without imposing directly a sense of order on them, then why should a library be so fussy about order? Again, the difficulties of those final weeks demonstrated a lack of engagement with planning developed over a period of two years. They have confirmed rather than frustrated the view that a school library needs to be in the face of the everyday activities of the school, so that it might be understood and used effectively. Also importantly, the specialist expertise and educational role of the library and its staff should be understood more widely, especially as they relate in the creation of more innovative and collaborative teaching and learning spaces.

3) Finally, the space itself. We were agreed to create a space in which students felt the offer to become engaged an inviting one. Teachers were to be part of the invitation, not as hosts, but as co-creators of the space. Glass classrooms, with nearly all walls fully opening, with no fixed teacher or screen positions and with little or no physical storage means that each time a class and a teacher occupy a classroom, the space seems ripe to made into something new and to live only until the class ends, when, except for writing on the glass walls, all traces of a presence should retreat, either to the internet, network or cloud or with the students themselves. What is left, written on the glass, something of a cave painting? In this sense the imperative to teach so that learning occurs is profound. For many of the teachers involved this is certainly a challenge to grow.

The Library will then help support the integration of such time and spatially fragmented, near invisible teaching and learning, firstly by its presence and secondly by its functions. Elmborg (2011) attempts a summary of Henri Lefebvre's work, The Production of Space, in which three ways of conceiving space are articulated: spatial practices, representations of space and representational spaces. The first two have been briefly addressed already. The third is about the ways in which people make use of the space as they live in it. "Representational space is individual, perceptual, intuitive, and symbolic." (p. 343) Between represented and representative spaces, the theorist Bhabha describes a dynamic new kind of space called the Third Space, 
originally conceived as being created when two or more cultures converge to occupy represented or dominated space (Elmborg, 2011). In our case, we have classroom cultures, student cultures, the library culture inherited from educated white middle class mores, as well as the cultural practices that staff and students bring with them from home. Negotiating the power differentials and the different interpretations of the space will necessitate users to transcend and, as has already begun, contest, the boundaries of their conceptions for the space to create a "more open, symbolic, playful and generative" (Elmborg, 2011, p.345) space. If this can be done as part of practice, every user of the library can cross the boundaries between classes, between what was and what might be, despite, or perhaps because of a kind of supportive orderliness. In this sense the Library staff are companions in the world of the school, to all who enter.

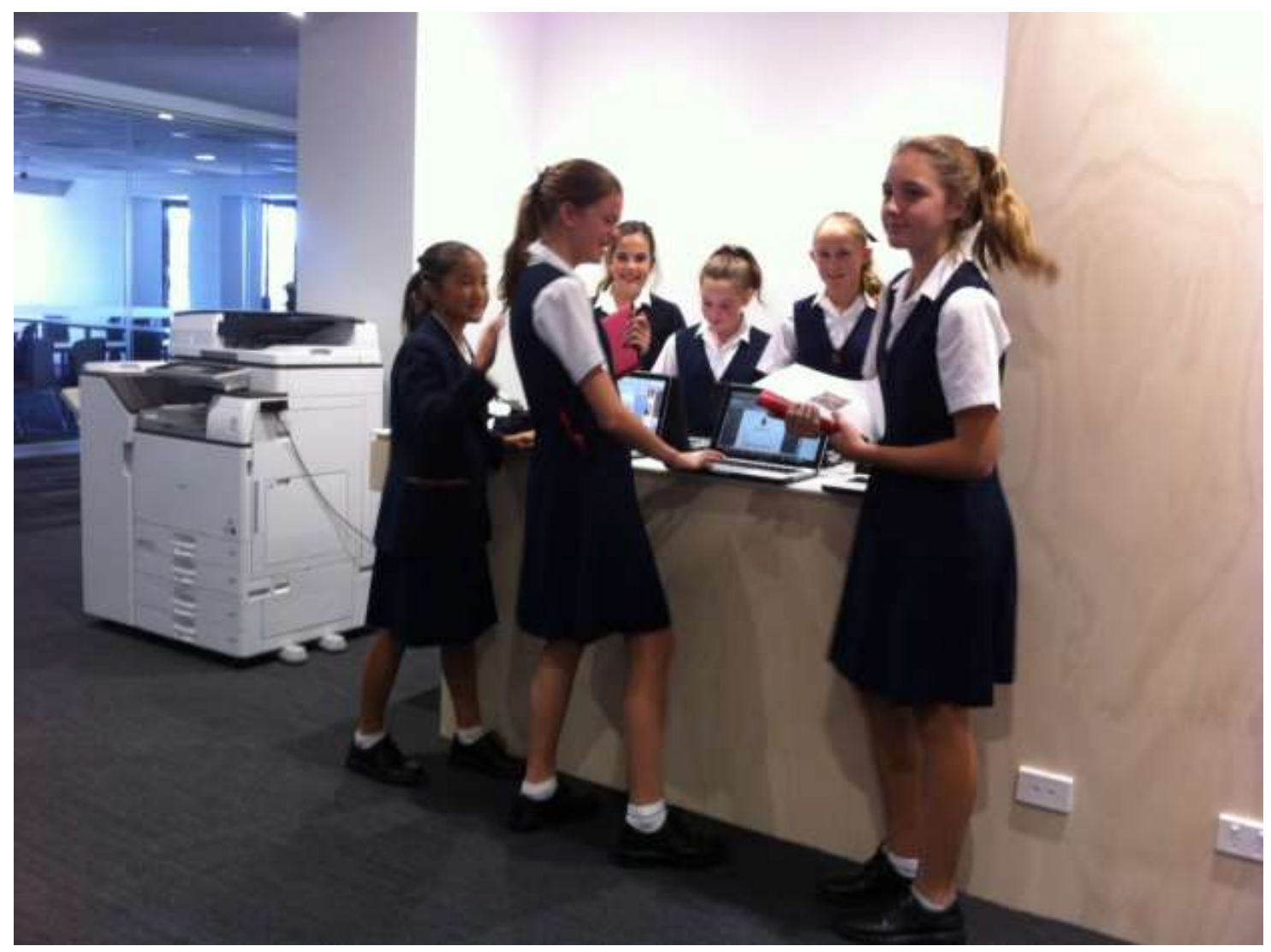

The print station

The space between the bibliographic librarian, the classroom pedagogue and the companion in a negotiated space is the one we have been travelling through these last two years. It will be interesting to see just what our new third space might be like. One of the most significant changes is that there is very little small group seating within the main library space. There is the sense that the classrooms themselves will become part of the library when not being taught in. Conceptually this is a huge leap. It is however in keeping with the trend that sees people of all ages and stages appropriating virtual and real spaces and making them their own. Such spaces are 
also made and remade flexibly. Conversations with distant relatives in trains, watching movies sitting in a covered walkway, lunching and even partying in the library are just some examples. Will the somewhat sterile ground of the warehouse style classroom finally be able to transmogrify?

\section{Flipping the third space}

Technology, in particular mobile technology, promises to release teaching and learning from many spatial and temporal restrictions so that almost any space can be a learning space at almost any time any time (Kearney et al., 2012). Yet, despite the level of comfort, fashionable design features or even comfort, it is the way in which spaces lend themselves to sociability and collaboration that mark out what students want in the spaces they occupy by choice (Crook, 2012).

There are thousands of documents, videos and websites related to flipping classroom teaching. Below are just three:

http://ctl.utexas.edu/teaching/flipping-a-class http://www.uq.edu.au/tediteach/flipped-classroom/what-is-fc.html https://www.youtube.com/watch?v=4JPdGlyt6gg https://net.educause.edu/ir/library/pdf/ELI7081.pdf (Seven things you should know about flipped classrooms)

https://net.educause.edu/ir/library/pdf/ELIR1302.pdf (Seven things you should read about flipped classrooms)

Each one emphasizes the value of increased time for social interaction embedded in pedagogy, at school, for enhancing learning and for creating a sense of ownership and belonging, some say a sense of place out of a space.

Flipping library (information literacy) instruction follows the same pattern. However, when it comes to flipping the library as a Third Space, the pattern is quite different. What I mean by flipping the Third Space is to work out and respond as a library to what it means to be a Third Space supporting flipped classrooms.

In flipped instruction, class time is more interactive, collaborative and exploration based. Higher order thinking and activities are central. Yet students do not necessarily do their flipped homework, study or research at home. Nor do they necessarily access classroom instruction from home. Depending on before and after school activities and family timetables, the library can be a site for any combination of all the modalities of the flipped and nonflipped classroom. Students and teachers have the opportunity to work flexibly with flipping. Missed class video and presentation modules can be watched "just in time" and classroom higher order interactions can call on an extended range of spaces, resources and, as appropriate, professional library support. Already, the Humanities Department for example, and they are not alone, while not formally flipping instruction, provides students with online reference materials for research topics as does the library. Students are encouraged to access such pre-prepared materials outside of class time. They then spend in-class time researching a topic of their own choice, supported in exploring widely beyond Google and accessing the range of expert personnel available. Such a space is both classroom and library and, because flexibility, choice and interactions are encouraged, can be a Third Space.

As a staff we decided to also experiment with extending our library hours. On a trial basis, our library will now be open from 7am to $8.30 \mathrm{pm}$ Monday to Thursday and from 7am to $5 \mathrm{pm}$ on Friday, during term time weeks. The library will continue to open from 1.30 to 4.30 on 
Sundays. From 5pm to 8.30 Monday to Thursday, the space will also be for Boarders (aged 12 to 18 years) Prep. At this time, yet another convergence of cultures occurs. Just as the idea of breaking down the walls of the classroom and the library are central to this project, so is opening up the mood and the facilities to Boarders doing homework alongside Day Girls. In providing such a space, some of the lock-step nature of year level, class, time, space and individual difference is loosened. Is there something helpful to an ethic of enquiry, study, cooperation and friendship in being part of such a shared enterprise? It will be curious to reflect on all this thinking and changing as the realities hit home.

\section{The first day}

The highlight of our first day was the overall positive response to a beautiful, if incomplete and not fully functioning, library. Classes desperately sought room to be there- even if it meant sitting on the floor or perched on a windowsill. We were asked to book three classes into the central part of the library- every class period if necessary. Despite there being next to no seating, they were there. The Lounge Room, even without any data or Wi-Fi connectivity was danced and sung in, as Vivaldi played. The old encyclopedias lending atmosphere and, well, weight, to the glass, the aluminium and even to the tasteful laminate prominent in the rest of the Library. Importantly, the lack of group homework seating was bemoaned. This is part of an overall issue with our space, I propose. There is a lack of nooks and crannies in the whole. We will have to make those slick, sleek glass classrooms able to be transformed more easily into something the students will feel is different from still being in a classroom.. We would like to, together, create and recreate private spaces in the whole as and when the teacher centered time gives way to individual and/or group use of the space. We will have to, after all, clutter up the smooth sweep of carpet between shelves for small groups "being and collaborating" together, by choice, here, in the library, out of school hours. As Wendy Stephens expresses it, the way forward for young adult libraries, in general, and our library in particular, is for them to evolve into a place for every learner, everywhere and all the time (Stephens, 2013).

\section{References}

Ali, T. (2013, October 01). Bring Your Dreams to the Library. Young Adult Library Services, (1), 45, Retrieved from http://elibrary.bigchalk.com

Australia., \& Rishworth, A. (2011). School libraries and teacher librarians in 21st century Australia. Canberra: Standing Committee on Education and Employment.

Crook, C. G. (2012). Ambience in social learning: student engagement with new designs for learning spaces. Cambridge Journal Of Education, 42(2), 121-139.

Davis, B. \& Sumara, D. (2008). Complexity as a theory of education. In Transnational Curriculum Inquiry 5 (2) 2008. http://nitinat.library.ubc.ca/ojs/index.php/tci

Elmborg, J. K. (June 01, 2011). Libraries as the spaces between us: Recognizing and valuing the third space. Reference and User Services Quarterly, 50, 4, 338-350.

Goodwin, B. (March 01, 2013). Evidence on flipped classrooms is still coming in. Educational Leadership, 70, 6, 78-80. 
Hung, D., Lim, K. Y. T., \& Lee, S.-S. (2014). Adaptivity as a transformative disposition: For learning in the 21 st century. Singapore: Springer.

Journell, W. (January 01, 2015). Practical Guidelines for Creating Online Courses in K-12 Education.

Kearney, M., Schuck, S., Burden, K., \& Aubusson, P. (2012). Viewing mobile learning from a pedagogical perspective. Research In Learning Technology, 20. doi:http://dx.doi.org/10.3402/rlt.v20i0.14406

Niemi, H., Toom, A., \& Kallioniemi, A. (2012). Miracle of education: The principles and practices of teaching and learning in Finnish Schools. Rotterdam: SensePublishers.

Rajala, A., Hilppö, J., Lipponen, L., \& Kumpulainen, K. (2013). Expanding the chronotopes of schooling for promotion of student's agency. In J. Shefton-Green \& O. Erstad (Eds.), Learning lives (pp. 107-125). Cambridge, UK: Cambridge University Press.

Snyder, S. (January 01, 2013). The simple, the complicated, and the complex: Educational reform through the lens of Complexity Theory. OECD Education Working Papers, no.96. Paris : Oecd Publishing, 2013.

Strand, R. (2007). Complexity, ideology and governance. In International Seminar on the Philosophical, Epistemological, and Methodological Implications of Complexity Theory, Capra, F., Instituto de Filosofía (Cuba. Ministerio de Ciencia, Tecnología y Medio Ambiente), \& Institute for the Study of Coherence and Emergence.

Reframing complexity: Perspectives from the north and south. Mansfield, MA: ISCE Pub.

Wendy, S. (2013, October 01). For Every Learner, Everywhere, All the Time: The Future of School Libraries. Young Adult Library Services, (1), 4, Retrieved from http://elibrary.bigchalk.com

Williams, T. (2013, October 01). Being Diverse in Our Support for STEM. Young Adult Library Services, (1), 24, Retrieved from http://elibrary.bigchalk.com

\section{Biographical note}

Robyn Markus-Sandgren has been Library Manager of St Hilda's School on the Gold Coast, Australia since 2002. Before that she was a teacher of Mathematics for ten years, a Resource Teacher (designing innovative programs with teachers and their schools) for ten years and a Fruit Shop owner with her husband and three children for ten years. After completing her Masters of Educational Studies at the University Of Queensland, Robyn found libraries and library technology. Robyn has never lost her interest in education itself, along with reading for pleasure. She has remained passionate about them all ever since. A polymath approach to life and work, including painting, psychology, writing poetry, yoga and gardening, has informed her commitment a Trans disciplinary approach to education. 